\title{
Safety and efficacy of etomidate and propofol anesthesia in elderly patients undergoing gastroscopy: A double-blind randomized clinical study
}

\author{
QING-TAO MENG $^{1 *}$, CHEN CAO $^{2 *}$, HUI-MIN LIU $^{1 *}$, ZHONG-YUAN XIA $^{1}$, WEI LI ${ }^{1}$, LING-HUA TANG $^{1}$, \\ RONG CHEN ${ }^{1}$, MENG JIANG ${ }^{1}$, YANG WU ${ }^{1}$, YAN LENG ${ }^{1}$ and CHRIS C. LEE $^{3}$ \\ ${ }^{1}$ Department of Anesthesiology, Renmin Hospital of Wuhan University; ${ }^{2}$ The Medical Department, \\ The Third Hospital of Wuhan, Wuhan, Hubei 430060, P.R. China; ${ }^{3}$ Department of Anesthesiology, \\ Washington University School of Medicine, St. Louis, MO 63110, USA
}

Received January 30, 2016; Accepted June 6, 2016

DOI: $10.3892 /$ etm.2016.3475

\begin{abstract}
The aim of the present study is to compare the safety, efficacy and cost effectiveness of anesthetic regimens by compound, using etomidate and propofol in elderly patients undergoing gastroscopy. A total of 200 volunteers (65-79 years of age) scheduled for gastroscopy under anesthesia were randomly divided into the following groups: $\mathrm{P}$, propofol $(1.5-2.0 \mathrm{mg} / \mathrm{kg}) ; \mathrm{E}$, etomidate $(0.15-0.2 \mathrm{mg} / \mathrm{kg}) ; \mathrm{P}+\mathrm{E}$, propofol $(0.75-1 \mathrm{mg} / \mathrm{kg})$ followed by etomidate $(0.075-0.1 \mathrm{mg} / \mathrm{kg})$; and $\mathrm{E}+\mathrm{P}$, etomidate $(0.075-0.01 \mathrm{mg} / \mathrm{kg})$ followed by propofol $(0.75-1 \mathrm{mg} / \mathrm{kg})$. Vital signs and bispectral index were monitored at different time points. Complications, induction and examination time, anesthesia duration, and recovery and discharge time were recorded. At the end of the procedure, the satisfaction of patients, endoscopists and the anesthetist were evaluated. The recovery $(6.1 \pm 1.2 \mathrm{~h})$ and discharge times $(24.8 \pm 2.8 \mathrm{~h})$ in group E were significantly longer compared with groups $\mathrm{P}, \mathrm{P}+\mathrm{E}$ and $\mathrm{E}+\mathrm{P}(\mathrm{P}<0.05)$. The occurrence of injection pain in group $\mathrm{P}+\mathrm{E}$ was significantly higher compared with the other three groups $(\mathrm{P}<0.05)$. In addition, the incidence of myoclonus and post-operative nausea and vomiting were significantly higher in group $\mathrm{P}+\mathrm{E}$ compared with the other three groups $(\mathrm{P}<0.05)$. There was no statistical difference among the four groups with regards to the patients' immediate, post-procedure satisfaction $(\mathrm{P}>0.05)$. Furthermore, there was no difference in the satisfaction of anesthesia, as evaluated by the anesthetist and endoscopist, among the four groups
\end{abstract}

Correspondence to: Professor Zhong-Yuan Xia, Department of Anesthesiology, Renmin Hospital of Wuhan University, 238 Jiefang Road, Wuhan, Hubei 430060, P.R. China

E-mail: xiazhongyuanmz@hotmail.com

*Contributed equally

Key words: anesthesia, gastroscopy, elderly patients, etomidate, propofol
( $P>0.05)$. The present study demonstrates that anesthesia for gastroscopy in elderly patients can be safely and effectively accomplished using a drug regimen that combines propofol with etomidate. The combined use of propofol and etomidate has unique characteristics which improve hemodynamic stability, cause minimal respiratory depression and less side effects, provide rapid return to full activity and result in high levels of satisfaction.

\section{Introduction}

Gastroscopy is a well-established, highly effective diagnostic and therapeutic procedure. The frequency of this procedure in the elderly is increasing rapidly as the general population ages $(1,2)$. Although it is a non-traumatic invasive procedure, it often causes significant discomfort in the majority of patients. With the collaboration of the anesthesia and digestive system departments, gastroscopy under anesthesia minimizes the risk of physical injury occurring during examination, and provides the endoscopist with a suitable environment for a thorough examination. This has been reported to be safe in high risk patients, including elderly, frail and seriously ill patients $(3,4)$. Despite the benefits of using anesthesia for gastroscopy, it has significant drawbacks. Anesthesia can delay patient recovery and discharge time, and increases the risk of cardiopulmonary complications, which are understood to account for $\sim 50 \%$ mortality and $\sim 60 \%$ morbidity associated with upper gastrointestinal endoscopy $(5,6)$. This risk is increased in elderly patients or those with cardiovascular diseases and upper gastrointestinal bleeding (7). Arterial hypoxemia, arrhythmias and myocardial ischemia have been reported following gastroscopy with anesthesia (7).

Anesthesia strategies for gastroscopy have been explored for decades. There are numerous reports on the safety profile of propofol used for anesthesia during gastrointestinal endoscopy (8-10). Propofol is currently the most frequently used intravenous anesthetic, due to its rapid recovery profile, and is widely used in outpatient surgeries and examinations $(4,10)$. The most prominent undesirable effect of propofol 
is its marked depression on cardiovascular and respiratory parameters, particularly in elderly patients (9-10). The distinct pharmacological characteristics of etomidate include improved hemodynamic stability and minimal respiratory depression (11). This results in a wider margin of safety for patients with significant risk factors, including patients with valvular heart disease and myocardial ischemia, and elderly patients. However, due to side effects, including myoclonus and post-operative nausea and vomiting (PONV), etomidate is rarely used in patients undergoing gastroscopy.

The aim of the present prospective study is to determine the safety, efficacy, cost effectiveness, side effect profile and recovery time of a combination of propofol and etomidate, compared with propofol and etomidate alone, as anesthetic regimens for gastroscopy.

\section{Materials and methods}

Patients and studydesign. The current study is a double-blinded, randomized, parallel-group study, performed in accordance with the International Conference on Harmonization Good Clinical Practice guidelines (8). The study was approved by the Ethics Committee of Renmin Hospital of Wuhan University (Wuhan, China), and informed consent was obtained from all patients. A total of 200 healthy, American Society of Anesthesiologists grade I-II patients, consisting of 97 males and 103 females, aged between 65 and 79 years, who were scheduled for gastroscopy with anesthesia, were included in the study. Patients had normal serum chemistry, and normal liver and renal function test results. No patients were experiencing cardiac or respiratory disease. Exclusion criteria included the following: Severe dysfunction of heart; lung, liver, kidney and adrenal insufficiency; sleep apnea syndrome; gastric retention; history of an allergic reaction to the study drugs; history of previous experience with endoscopy; patients receiving analgesics, such as nonsteroidal anti-inflammatory drugs; patients administered $\alpha$-methyldopa, clonidine or a $\beta$-blocker; patients with psychiatric, neurological or neuromuscular disorders; or patients who had used drugs, drank alcohol or smoked tobacco two weeks prior to the study. Demographic data obtained included age, weight, gender and primary diagnosis. Propofol and etomidate doses, administered by bolus and continuous infusion, were recorded.

Medicine preparation, anesthesia monitoring and gastroscopy procedure. Drugs used in the study included $200 \mathrm{mg} / 20 \mathrm{ml}$ propofol (AstraZeneca, London, UK), $20 \mathrm{mg} / 10 \mathrm{ml}$ etomidate (Nhwa Pharmaceutical Group, Jiangsu, China) and 100 mg/2 ml fentanyl (Yichang Humanwell Pharmaceutical Co., Ltd., Yichang, China). Etomidate and propofol were diluted to $20 \mathrm{ml}$ prior to administration. All dugs were prepared by an anesthesiologist who was blinded to the study. An investigator, who was blinded to group assignment, assessed and recorded all observed parameters.

In accordance with hospital policies regarding procedural anesthesia, fasting status was confirmed, and a 20 -gauge peripheral IV catheter was placed in the right forearm without subcutaneous local anesthesia following the arrival of patients to the Digestive Endoscopy Center of Renmin Hospital of Wuhan University. Lactated Ringer's solution
(Baxter International Inc., Deerfield, IL, USA) was infused, and routine monitoring consisting of a 5-lead electrocardiography (ECG), non-invasive blood pressure, pulse oxygen saturation $\left(\mathrm{SpO}_{2}\right)$ and bispectral index (BIS; Monitor Model A-2000; Aspect Medical Systems, Inc., Norwood, MA, USA). The mean of the final 3 vital signs obtained prior to the injection of anesthetics was recorded as the baseline in all patients. After lying on the examination table in the left lateral position, each patient was provided oxygen $(5 \mathrm{l} / \mathrm{min})$ via a face mask and instructed to take deep breathes to increase their oxygen reserves.

All patients received intravenous (i.v.) $1 \mu \mathrm{g} / \mathrm{kg}$ fentanyl at 5-10 sec prior to gastroscopy. Prior to endoscopy, patients were randomized to one of four groups using a computer-generated random numbers table, which allocated 50 patients to each group. Patients in the propofol group (P) received i.v. propofol at an induction dose of 1.5-2.0 $\mathrm{mg}$. $\mathrm{kg}^{-1}$ over a 1 min period using a computer controlled infusion pump (Syringe Infusion Pump Model compact; B. Braun Melsungen AG, Melsungen, Germany), followed by a maintenance infusion of $4 \mathrm{mg} \cdot \mathrm{kg}^{-1} \cdot \mathrm{h}^{-1}$ during the gastroscopy procedure. Patients in the etomidate group (E) received i.v. etomidate at an induction dose of $0.15-0.2 \mathrm{mg} / \mathrm{kg}$ over $1 \mathrm{~min}$ using the same infusion pump, followed by a maintenance infusion of $0.4 \mu \mathrm{g} \cdot \mathrm{kg}^{-1} \cdot \mathrm{h}^{-1}$ during the gastroscopy procedure. Patients in the propofol and etomidate group $(\mathrm{P}+\mathrm{E})$ received propofol $(0.75-1 \mathrm{mg} / \mathrm{kg})$ over a $30 \mathrm{sec}$ period and subsequently etomidate $(0.075-0.1 \mathrm{mg} / \mathrm{kg})$ over a $30 \mathrm{sec}$ period using the same infusion pump, followed by a maintenance infusion of $2 \mathrm{mg} \cdot \mathrm{kg}^{-1} \cdot \mathrm{h}^{-1}$ propofol and $0.2 \mu \mathrm{g} \cdot \mathrm{kg}^{-1} \cdot \mathrm{h}^{-1}$ etomidate simultaneously during the gastroscopy procedure via a three-way joint. Patients in the etomidate and propofol group $(\mathrm{E}+\mathrm{P})$ received etomidate $(0.075-0.01 \mathrm{mg} / \mathrm{kg})$ over a 30 -sec period and subsequently propofol $(0.75-1 \mathrm{mg} / \mathrm{kg})$ over a $30 \mathrm{sec}$ period via the same infusion pump, followed by a maintenance infusion of $2 \mathrm{mg} \cdot \mathrm{kg}^{-1} \cdot \mathrm{h}^{-1}$ propofol and $0.2 \mu \mathrm{g} \cdot \mathrm{kg}^{-1} \cdot \mathrm{h}^{-1}$ etomidate during the gastroscopy procedure via a three-way joint.

Gastroscopy was performed when eyelash reflexes disappeared. The gastroscopy was performed with patients in a left lateral position, using a side-viewing video duodenoscope (Olympus Optical Co., Ltd., Tokyo, Japan). An anesthetist was in attendance during all procedures. Spontaneous respiration was maintained during the course of gastroscopy.

Observed parameters. A 5-lead ECG was performed throughout the gastroscopy. In addition, reductions in $\mathrm{SpO}_{2}$, changes in heart rate (HR) and blood pressure (BP), ST segment deviations, arrhythmias and conduction defects were recorded throughout the procedure. Vital signs were recorded at T0 (baseline, prior to induction of anesthesia), T1 (2 min after induction of anesthesia), T2 (4 min after induction of anesthesia), T3 (6 min after induction of anesthesia), T4 (8 min after induction of anesthesia), T5 (10 min after induction of anesthesia), T6 (15 min after induction of anesthesia) and T7 (20 min after induction of anesthesia).

Patients were assessed at the following time points for various complications: i) Start of anesthesia (first drug bolus); ii) start of examination (gastroscopy placement); iii) completion of the examination (removal of the 
gastroscopy); iv) 'induction time' (start of anesthesia to start of examination); v) 'inspection time' (gastroscopy insertion to gastroscopy removal); vi) 'recovery time' (the time between the gastroscopy removal and the start of the final psychometric assessment); and vii) 'discharge time' (the time between gastroscopy removal and departure from the endoscopy unit). The criteria for discharge from the endoscopy unit were as follows: Fully awake with stable hemodynamics; no evidence of respiratory depression; no nausea or vomiting; and ability to drink water safely.

Rate pressure product (RPP) and pressure-rate quotient (PRQ) (12), which are two indices that reflect myocardial oxygen consumption, were calculated following the examination as follows: RPP $=$ systolic blood pressure $(\mathrm{SBP}) \mathrm{x}$ heart rate $(\mathrm{HR}) / 1,000 ; \mathrm{PRQ}=$ mean arterial pressure $/ \mathrm{HR}$.

Adverse events, the use of ventilator support, including support of the oral or nasopharyngeal airways, and the administration of pressors and chronotropic agents were recorded. Bradycardia was defined as a heart rate $<50$ beats per minute (bpm). Hypotension was defined as a systolic pressure $<70 \%$ baseline or $<80 \mathrm{mmHg}$. Side effects, including PONV, swallowing, body movement (limb locomotor activity with no influence on gastroscopy), serious body movements (resulting in suspension of the examination), apnea (interval time of respiration, $>30 \mathrm{sec})$, hypoxemia $\left(\mathrm{SpO}_{2},<90 \%\right)$, myoclonus (involuntary and brief twitching of a group of muscles) and injection pain, were recorded.

At the end of the procedure, the satisfaction of the anesthetist and gastroenterologist were evaluated according to the visual analogue scale (13) (VAS scores; $0=$ no satisfaction and $10=$ most satisfaction). A questionnaire, which inquired about i) overall satisfaction with the anesthesia, ii) difficulty of anesthesia, iii) patient cooperation, and iv) overall satisfaction with the gastroscopy procedure, was used.

Prior to discharge, patient satisfaction was evaluated by completing an anonymous and confidential Patient Satisfaction Questionnaire, modified from Sipe (14), to evaluate the endoscopy experience.

Safety equipment. Vital signs were monitored for $2 \mathrm{~h}$ after the completion of the examination. The incidence of the following cardiorespiratory events were recorded: Bradycardia; respiratory depression ( $\mathrm{RR}$; <9 breaths/min); apnea; hypertension (BP $>30 \%$ baseline); and hypotension ( $\mathrm{BP}<30 \%$ baseline). Intervention, including the administration of fluid, pressors, or the use of an anticholinergic agents, was applied for any adverse events. Mask-assisted ventilation was performed if $\mathrm{SpO}_{2}<90 \%$ remained for $30 \mathrm{sec}$. Additionally, any events resulting in mortality, permanent impairment, hospitalization and/or medical or surgical intervention were recorded.

Statistical analysis. Data are presented as the mean \pm standard deviation, and medians. GraphPad Prism version 5.0 (GraphPad Software, Inc., San Diego, CA, USA) was used to analyze the results. One-way analysis of variance was performed to examine differences among the four groups with respect to parametric variables, followed by Tukey's post hoc test. Incidences of complications were analyzed using the $\chi^{2}$ or Fisher's exact test. $\mathrm{P}<0.05$ was considered to indicate a statistically significant difference.

\section{Results}

Combined use of propofol and etomidate reduces recovery and discharge times, as compared with etomidate alone. A total of 253 patients were assessed for study eligibility; 35 patients did not meet the inclusion criteria, 15 patients declined to participate and 3 patients were excluded for other reasons (Fig. 1). In total, 200 patients were included in the study (97 males and 103 females; age range, 65-82 years). The four groups had similar demographic data $(\mathrm{P}>0.05$; Table I) and BIS ( $\mathrm{P}>0.05$; Table I). The induction time, inspection time and anesthesia duration were not different between the four groups (P>0.05; Fig. 2). The recovery $(6.1 \pm 1.2 \mathrm{~h})$ and discharge times $(24.8 \pm 2.8 \mathrm{~h})$ in group $\mathrm{E}$ were longer compared with group $\mathrm{P}(4.8 \pm 0.9 \mathrm{~h}$ and $22.7 \pm 2.8 \mathrm{~h}$, respectively), group $\mathrm{P}+\mathrm{E}(5.2 \pm 0.9 \mathrm{~h}$ and $23.6 \pm 1.4 \mathrm{~h}$, respectively) and group $\mathrm{E}+\mathrm{P}$ (5.3 $\pm 0.8 \mathrm{~h}$ and $23.5 \pm 1.8 \mathrm{~h}$, respectively) $(\mathrm{P}<0.05$; Fig. 2$)$. No gastroscopy procedure was terminated because of inadequate patient anesthesia.

Etomidate improves hemodynamic stability, as compared with propofol. A decrease in BP $>30 \%$ from the baseline occurred in 62 patients across all groups (Table II). There was a decrease in SBP from the baseline in all patients at T1, and there was a significant difference in the incidence of hypotension in group $\mathrm{P}$, as compared with the other three groups (88\%; $\mathrm{P}<0.05$; Fig. 3). In addition, there were statistically significant differences in SBP in group P at T1, as compared with the other three groups $(\mathrm{P}<0.05$; Fig. 3$)$, and there were significant differences in SBP at T0 compared with T1, T2, T3, T4, T5 and T6 in group $\mathrm{P}(\mathrm{P}<0.05$; Fig. 3). Furthermore, there was a significant difference in SBP at T0 compared with T1, T2, T3, T4 and $\mathrm{T} 5$ in groups $\mathrm{E}, \mathrm{P}+\mathrm{E}$ and $\mathrm{E}+\mathrm{P}(\mathrm{P}<0.05$; Fig. 3). Moreover, in groups $\mathrm{E}, \mathrm{P}+\mathrm{E}$ and $\mathrm{E}+\mathrm{P}$, there was a significant difference in SBP at T1 $(132.08 \pm 6.56,129.56 \pm 6.58$ and $131.20 \pm 5.93 \mathrm{mmHg}$, respectively) compared with T6 $(151.28 \pm 5.73,150.72 \pm 5.79$ and $152.16 \pm 6.65 \mathrm{mmHg}$, respectively) and $\mathrm{T} 7(157.44 \pm 5.36$, $154.36 \pm 8.04$ and $158.68 \pm 5.71 \mathrm{mmHg}$, respectively) $(\mathrm{P}<0.05$; Fig. 3). The results for the other three groups showed improved hemodynamic stability compared with group $\mathrm{P}(\mathrm{P}<0.05$, Fig. 3). There were no significant differences in the mean and maximum HR during gastroscopy in different groups $(\mathrm{P}>0.05$, Fig. 3). It has been suggested that $R P P \geq 12$ indicates myocardial ischemia (12), and that RPP $\geq 20$ is a threshold for angina pectoris; PRQ $<1.0$ is considered to be an accurate measure of myocardial ischemia. In the present study, 1 patient had a very high RPP (>20), and 2 patients had PRQ $<1.0$, in group P.

Combined use of propofol and etomidate causes minimal respiratory depression and few side effects. The incidences of complications resulting from gastroscopy are presented in Table II. No serious complication occurred during the study. Transient hypoxia $\left(\mathrm{SpO}_{2},<90 \%\right.$ for $\left.>30 \mathrm{sec}\right)$ requiring supplemental oxygen by mask-assisted ventilation occurred in 7 patients across all groups (Table II). All episodes of hypotension and bradycardia were transient, and the administration of a pharmacologic agent or other therapeutic intervention was not required to treat any of the patients. No perforations or mortality occurred, and following the procedure, no patient required assisted ventilation or was admitted to hospital. 
Table I. Patient demographics.

\begin{tabular}{lcccc}
\hline & \multicolumn{3}{c}{ Group } & \\
\cline { 2 - 5 } Parameter & $\mathrm{P}$ & $\mathrm{E}$ & $\mathrm{P}+\mathrm{E}$ & $\mathrm{E}+\mathrm{P}$ \\
\hline Median age (range), years & $68.4(65-78)$ & $69.7(65-80)$ & $72.3(65-79)$ & $24 / 26$ \\
Gender, male/female & $24 / 26$ & $25 / 25$ & $6(65-82)$ \\
Median weight (range), $\mathrm{kg}$ & $60.7(50-84)$ & $62.4(52-82)$ & $62.6(47-85)$ & $61.8(49-84)$ \\
\hline
\end{tabular}

There are no significant difference between the treatment groups $(\mathrm{P}>0.05)$. $\mathrm{P}$, propofol $(1.5-2.0 \mathrm{mg} / \mathrm{kg}) ; \mathrm{E}$, etomidate $(0.15-0.2 \mathrm{mg} / \mathrm{kg}) ; \mathrm{P}+\mathrm{E}$, propofol $(0.75-1 \mathrm{mg} / \mathrm{kg})$ followed by etomidate $(0.075-0.1 \mathrm{mg} / \mathrm{kg})$; E+P, etomidate $(0.075-0.01 \mathrm{mg} / \mathrm{kg})$ followed by propofol $(0.75-1 \mathrm{mg} / \mathrm{kg})$.

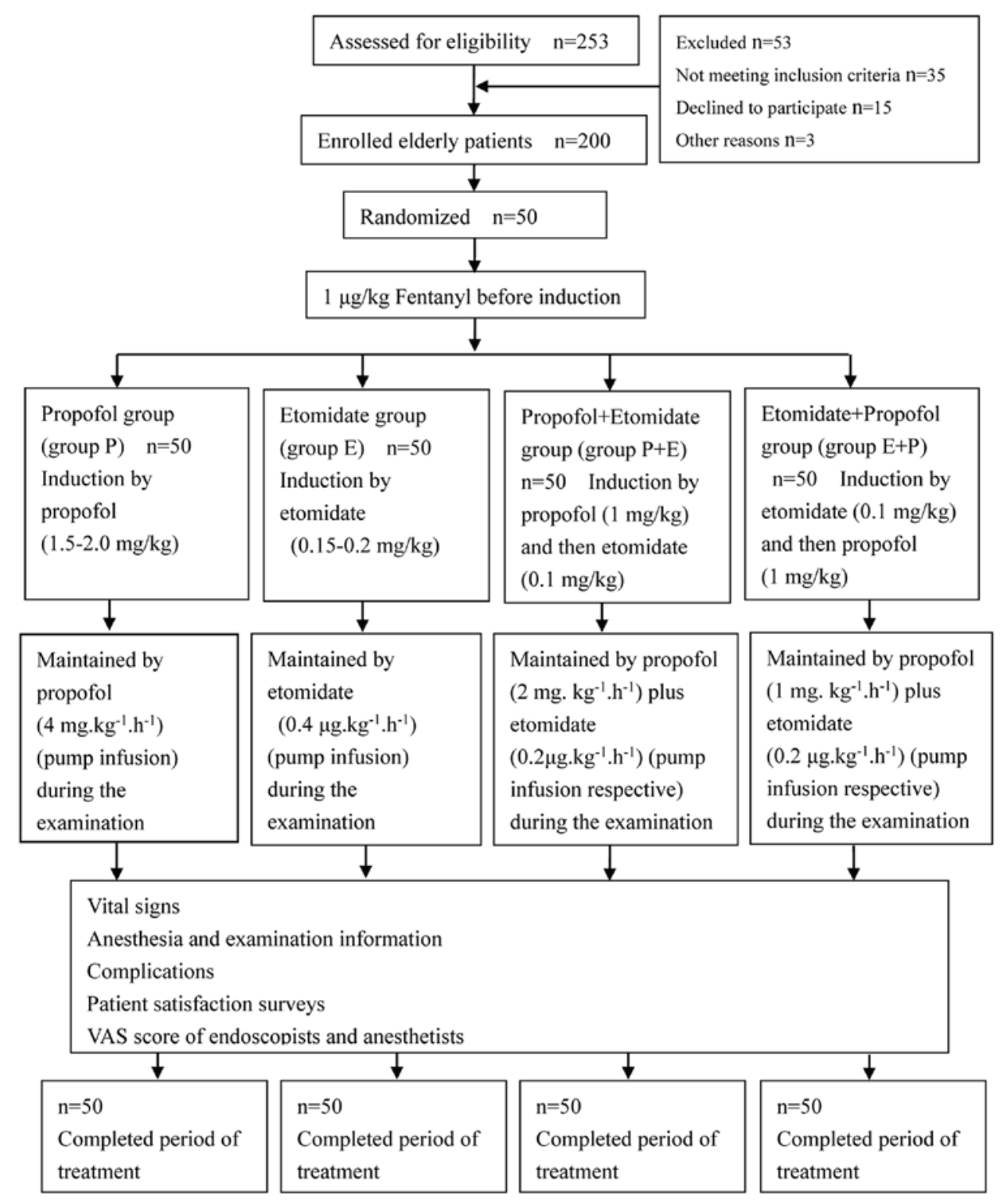

Figure 1. Study profile. Flow diagram of the phases of the randomized trial.

The occurrence of apnea during and following gastroscopy was $17 \%$ (34); $2 \%$ of these patients had $\mathrm{SpO}_{2}<90 \%$, and $2.5 \%$ of the patients reported accessing mask-assisted ventilation in the endoscopy unit. The occurrence of $\mathrm{SpO}_{2}<95 \%(24 \%)$, $\mathrm{SpO}_{2}<90 \%(8 \%)$, apnea (42\%) and mask-assisted ventilation
$(8 \%)$ in group $\mathrm{P}$ were significant higher compared with groups $\mathrm{E}(4,0,14$ and $2 \%$, respectively), $\mathrm{P}+\mathrm{E}(6,0,6$ and $2 \%$, respectively) and $\mathrm{E}+\mathrm{P}(6,0,6$ and $2 \%$, respectively) $(\mathrm{P}<0.05$; Table II). There were no significant differences in the occurrence of $\mathrm{SpO}_{2}<95 \%, \mathrm{SpO}_{2}<90 \%$, apnea, and mask-assisted 
A

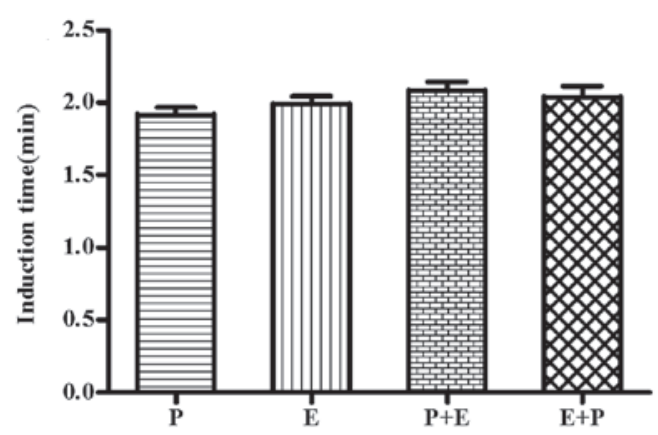

C

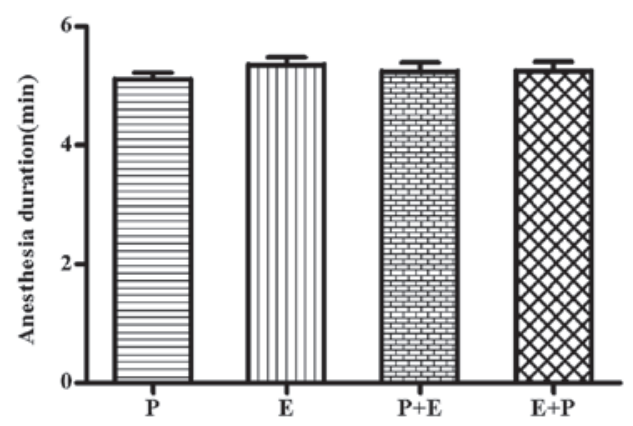

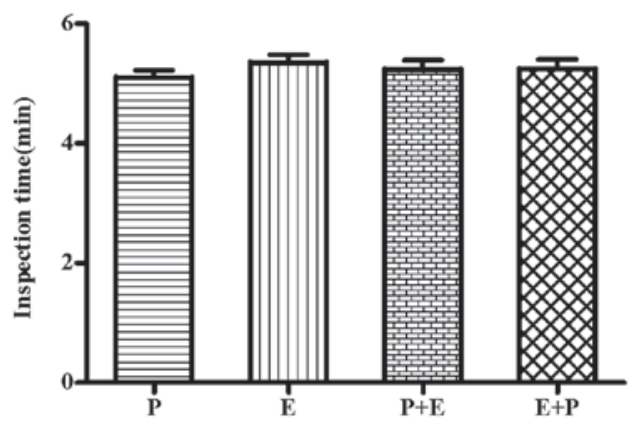

D

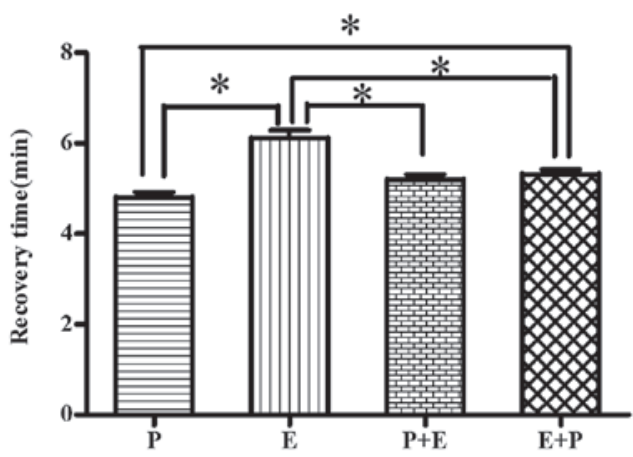

$\mathbf{E}$

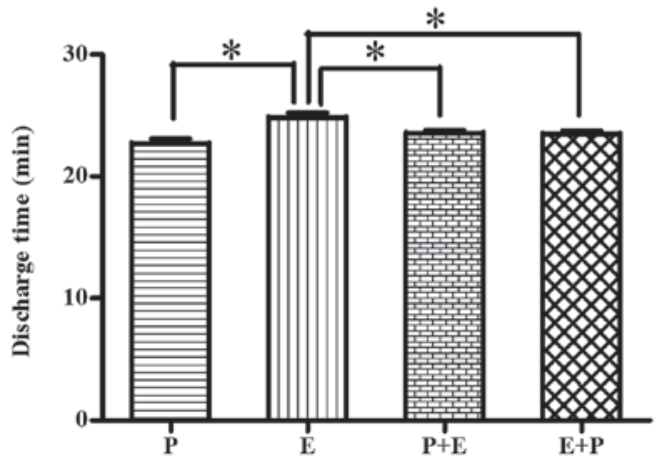

Figure 2. (A) Induction time, (B) inspection time, (C) anesthesia duration, (D) recovery time and (E) discharge time of the four study groups (n=50). Data are presented as the mean \pm standard deviation. ${ }^{*} \mathrm{P}<0.05$. P, propofol $(1.5-2.0 \mathrm{mg} / \mathrm{kg})$; E, etomidate $(0.15-0.2 \mathrm{mg} / \mathrm{kg}) ; \mathrm{P}+\mathrm{E}, \mathrm{propofol}(0.75-1 \mathrm{mg} / \mathrm{kg}) \mathrm{followed}$ by etomidate $(0.075-0.1 \mathrm{mg} / \mathrm{kg}) ; \mathrm{E}+\mathrm{P}$, etomidate $(0.075-0.01 \mathrm{mg} / \mathrm{kg})$ followed by propofol $(0.75-1 \mathrm{mg} / \mathrm{kg})$.

ventilation when comparing groups $\mathrm{E}, \mathrm{P}+\mathrm{E}$ and $\mathrm{E}+\mathrm{P}(\mathrm{P}>0.05$ Table II).

ECG changes during and following gastroscopy occurred in $22.5 \%$ of all procedures. In group P, related transient ECG changes included ST segment depression (20\%), transient atrial fibrillation (4\%), sinus bradycardia (10\%) and ventricular premature complexes (2\%). In group E, sinus bradycardia occurred in $12 \%$ of procedures and ST segment changes occurred in $6 \%$ of patients. In group $\mathrm{P}+\mathrm{E}$, the occurrence of bradycardia was $10 \%$, and ST segment changes occurred in $8 \%$ of patients. In the $\mathrm{E}+\mathrm{P}$ group, sinus bradycardia occurred in $8 \%$ and ST changes occurred in $6 \%$ of patients. The difference in the incidence of arrhythmia and ischemic changes between the four groups was not significant $(\mathrm{P}>0.05$; Table II).

The occurrence of myoclonus during and following gastroscopy with anesthesia in group E (30\%) was significantly higher compared with groups P (2\%), P+E (4\%) and
$\mathrm{E}+\mathrm{P}(6 \%)(\mathrm{P}<0.05)$. The occurrence of injection pain during and following gastroscopy in group $\mathrm{P}(64 \%)$ was significantly higher compared with groups $\mathrm{E}(6 \%), \mathrm{P}+\mathrm{E}(20 \%)$ and $\mathrm{E}+\mathrm{P}(6 \%)$ $(\mathrm{P}<0.05)$. The occurrence of injection pain in group $\mathrm{P}+\mathrm{E}$ was significant higher compared with groups $\mathrm{E}$ and $\mathrm{E}+\mathrm{P}(\mathrm{P}<0.05)$. There were no statistical differences between groups $\mathrm{P}$ and $\mathrm{E}$ with regards to the occurrence of body movements $(\mathrm{P}>0.05$; Table II). One patient moved significantly enough to require suspension of the gastroscopy while additional propofol was given. The occurrence of body movements significantly decreased using propofol and etomidate together, regardless of which drug was administered first $(\mathrm{P}<0.05$; Table II). Body movements occurred in 42 patients $(21 \%)$, the majority of which were general body movements $(97.6 \%)$. The incidence of PONV in group E (14\%) was significantly higher compared with group $\mathrm{P}(8 \%)(\mathrm{P}<0.05$; Table II). There was no statistical difference in the incidence of $\mathrm{PONV}$ between groups $\mathrm{P}, \mathrm{P}+\mathrm{E}$ and $\mathrm{E}+\mathrm{P}$. 

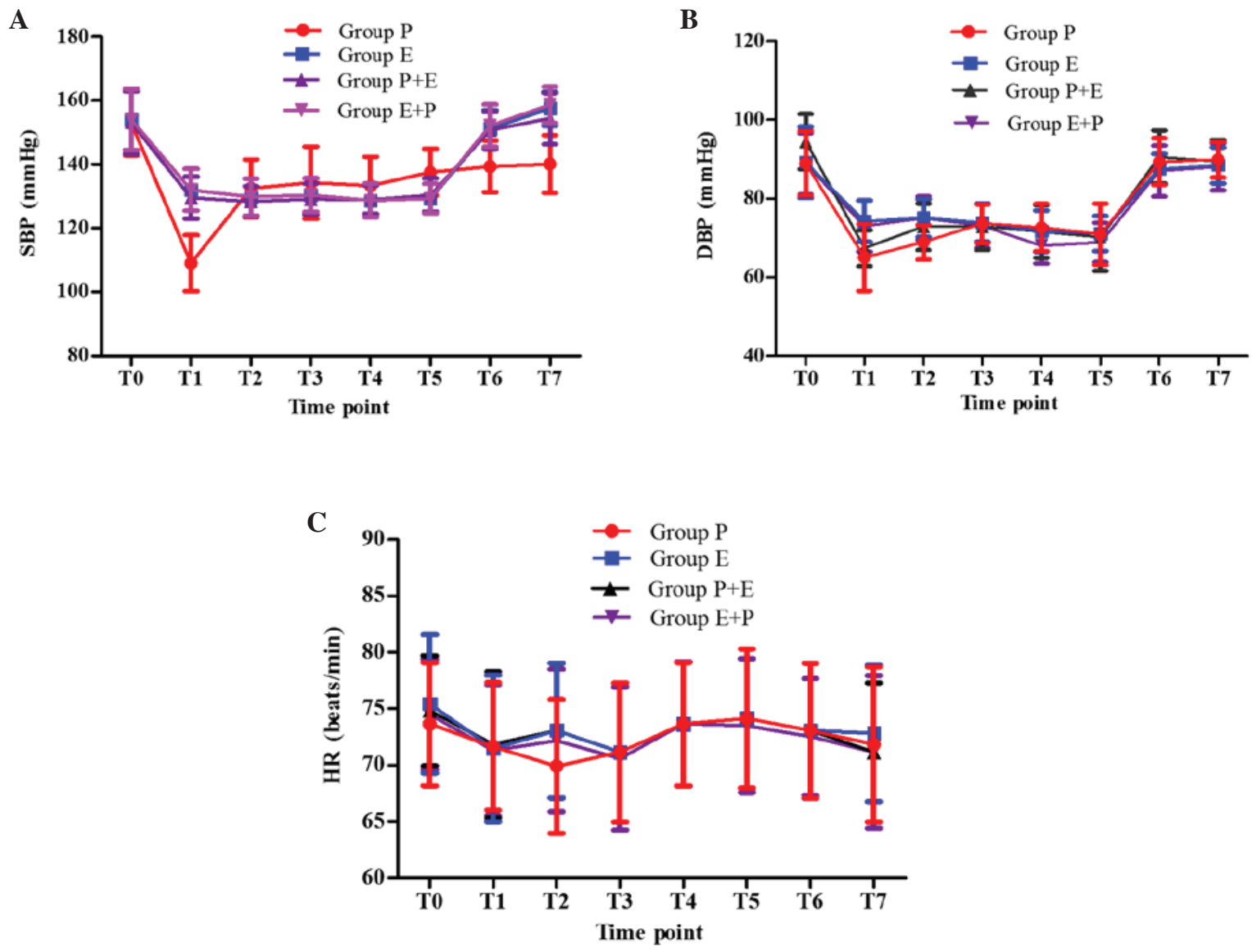

Figure 3. Mean (A) SBP, (B) DBP and (C) HR levels of the four study groups ( $\mathrm{n}=50)$ during gastroscopy. Data are presented as the mean \pm standard deviation. There was a significant difference between SBP in group $\mathrm{P}$ at $\mathrm{T} 1$ compared with T0 $(\mathrm{P}<0.05)$, and there were significant differences in SBP at T0 compared with SBP at T1, T2, T3, T4, T5 and T6 in group $\mathrm{P}(\mathrm{P}<0.05)$. In addition, there were significant differences in SBP at T0 compared with T1, T2, T3, T4 and T5 in groups $\mathrm{E}, \mathrm{P}+\mathrm{E}$ and $\mathrm{E}+\mathrm{P}(\mathrm{P}<0.05)$. Furthermore, there were significant differences in SBP at T1 compared with T6 and T7 in groups $\mathrm{E}, \mathrm{P}+\mathrm{E}$ and $\mathrm{E}+\mathrm{P}$ $(\mathrm{P}<0.05)$. However, there were no significant differences in HR in any groups $(\mathrm{P}>0.05)$. SBP, systolic blood pressure; DBP, diastolic blood pressure; HR, heart rate; $\mathrm{P}$, propofol (1.5-2.0 mg/kg); E, etomidate (0.15-0.2 mg/kg); P+E, propofol (0.75-1 mg/kg) followed by etomidate (0.075-0.1 mg/kg); E+P, etomidate $(0.075-0.01 \mathrm{mg} / \mathrm{kg})$ followed by propofol $(0.75-1 \mathrm{mg} / \mathrm{kg})$.

Combination of propofol and etomidate increases patient satisfaction following a gastroscopy, as compared with using either agent alone. Patient evaluation of the gastroscopy is presented in Table III. The immediate post-procedure questionnaire was completed by all patients. In group P, $90 \%$ of patients described their overall satisfaction with the anesthesia as 'excellent' and $10 \%$ rated it 'good' when asked to rate the degree of pain or discomfort experienced during the endoscopy. Meanwhile, in group E, $80 \%$ of patients described overall satisfaction as 'excellent', $12 \%$ described it as 'good' and $8 \%$ of patients described it as 'fair'. In the $\mathrm{P}+\mathrm{E}$ and $\mathrm{E}+\mathrm{P}$ groups, overall satisfaction was rated as excellent in 90 and $92 \%$ of patients, respectively, which is significantly increased compared with groups $\mathrm{P}$ and $\mathrm{E}$ ( $\mathrm{P}>0.05$; Table III).

In group $\mathrm{P}, 80 \%$ of patients reported no discomfort, $16 \%$ described discomfort as mild, and $4 \%$ described discomfort as moderate; $90 \%$ of patients rated the level of anesthesia as 'adequate', 8\% believed that they received 'too little', and 2\% stated that they were given 'too much'. In group E, $72 \%$ of patients reported no discomfort, $24 \%$ described discomfort as mild and $4 \%$ described discomfort as moderate; $92 \%$ of patients rated the level of anesthesia as 'adequate', 6\% believed that they received 'too little' and $2 \%$ stated that they were given 'too much'. In groups $\mathrm{P}+\mathrm{E}$ and $\mathrm{E}+\mathrm{P}, 80$ and $78 \%$ reported no discomfort, respectively, 18 and $20 \%$ described discomfort as mild, respectively, and $2 \%$ in both groups described discomfort as moderate. All patients rated the level of anesthesia as 'adequate' when asked to rate the level of anesthesia during the endoscopy following co-administration of propofol and etomidate ( $\mathrm{P}>0.05$; Table III).

Combination of propofol and etomidate provides Although the survey was conducted $24 \mathrm{~h}$ after discharge, it was shown that different proportions of patients in the four groups returned to normal activities within $2 \mathrm{~h}$ of discharge. Group $\mathrm{P}$ patients required $\geq 4 \mathrm{~h}$ before resumption of activities, although the majority of patients did not require additional sleep following discharge from the endoscopy unit. There were no statistical differences between group $\mathrm{P}$ and the other three groups with regard to the patients' immediate and post-procedure satisfaction ( $\mathrm{P}>0.05$; Table III). Finally, in the present study, a combination of propofol and etomidate provided better satisfaction of endoscopists $(\mathrm{P}<0.05)$ and anesthetists $(\mathrm{P}<0.01)$ compared with using propofol alone (Fig. 4).

\section{Discussion}

The results of the present study demonstrate that there is improved hemodynamic stability and minimal respiratory 
Table II. Complications of the four study groups $(\mathrm{n}=50)$.

\begin{tabular}{|c|c|c|c|c|}
\hline \multirow[b]{2}{*}{ Parameter } & \multicolumn{4}{|c|}{ Group } \\
\hline & $\mathrm{P}$ & $\mathrm{E}$ & $\mathrm{P}+\mathrm{E}$ & $\mathrm{E}+\mathrm{P}$ \\
\hline Hypotension & $44(88)$ & $6(12)^{\mathrm{a}}$ & $6(12)^{a}$ & $6(12)^{\mathrm{a}}$ \\
\hline ST segment depression & $10(20)$ & $3(6)^{\mathrm{a}}$ & $4(8)^{\mathrm{a}}$ & $3(6)^{\mathrm{a}}$ \\
\hline Transient atrial fibrillation & $2(4)$ & $0(0)$ & $0(0)$ & $1(2)$ \\
\hline Sinus bradycardia & $5(10)$ & $6(12)$ & $5(10)$ & $4(8)$ \\
\hline Ventricular premature complexes & $1(2)$ & $0(0)$ & $0(0)$ & $1(2)$ \\
\hline $\mathrm{SpO}_{2}<95 \%$ & $12(24)$ & $2(4)^{\mathrm{a}}$ & $3(6)^{\mathrm{a}}$ & $3(6)^{\mathrm{a}}$ \\
\hline $\mathrm{SpO}_{2}<90 \%$ & $4(8)$ & $0(0)^{\mathrm{a}}$ & $0(0)^{\mathrm{a}}$ & $0(0)^{\mathrm{a}}$ \\
\hline Apnea & $21(42)$ & $7(14)^{\mathrm{a}}$ & $3(6)^{\mathrm{a}}$ & $3(6)^{\mathrm{a}}$ \\
\hline Mask assisted ventilation & $4(8)$ & $1(2)^{\mathrm{a}}$ & $1(2)^{\mathrm{a}}$ & $1(2)^{\mathrm{a}}$ \\
\hline Body movements & $13(26)$ & $18(36)$ & $5(10)^{\mathrm{b}}$ & $6(12)^{b}$ \\
\hline Body movements, general & $12(24)$ & $18(36)$ & $5(10)$ & $6(12)$ \\
\hline Body movements, serious & $1(2)$ & $0(0)$ & $0(0)$ & $0(0)$ \\
\hline Myoclonus & $1(2)$ & $15(30)^{\mathrm{a}}$ & $2(4)$ & $3(6)$ \\
\hline Injection pain & $32(64)$ & $3(6)^{\mathrm{a}}$ & $10(20)^{a, b}$ & $3(6)^{\mathrm{a}}$ \\
\hline PONV & $4(8)$ & $7(14)^{\mathrm{a}}$ & $5(10)$ & $6(12)$ \\
\hline
\end{tabular}

Data are $\mathrm{n}(\%)$. ${ }^{\mathrm{a}} \mathrm{P}<0.05$, vs. group $\mathrm{P},{ }^{\mathrm{b}} \mathrm{P}<0.05$, vs. group E. SpO2, pulse oxygen saturation; PONV, post-operative nausea and vomiting.

A

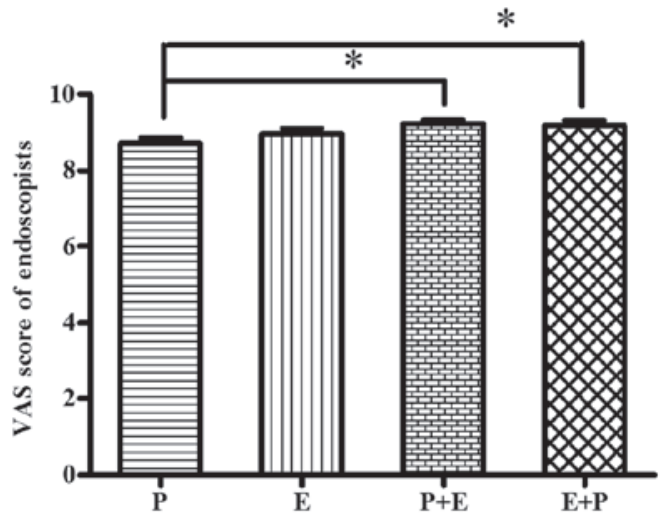

B

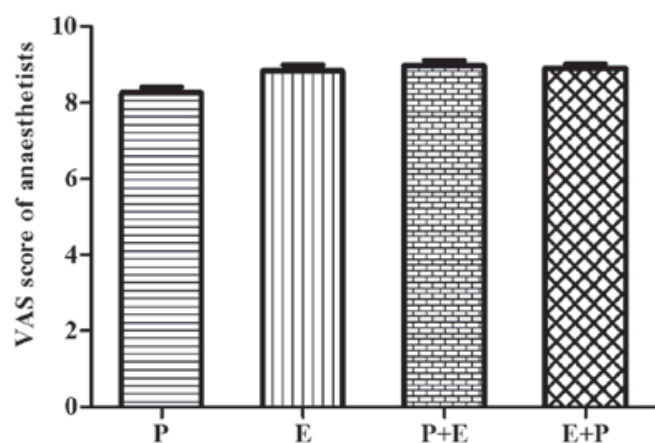

Figure 4. VAS score of (A) endoscopists and (B) anaesthetists of the four study groups $(\mathrm{n}=50)$. Data are presented as the mean \pm standard deviation. ${ }^{*} \mathrm{P}<0.05$, vs. group P; VAS, visual analogue scale; $\mathrm{P}$, propofol $(1.5-2.0 \mathrm{mg} / \mathrm{kg})$; $\mathrm{E}$, etomidate $(0.15-0.2 \mathrm{mg} / \mathrm{kg}) ; \mathrm{P}+\mathrm{E}$, propofol $(0.75-1 \mathrm{mg} / \mathrm{kg})$ followed by etomidate $(0.075-0.1 \mathrm{mg} / \mathrm{kg}) ; \mathrm{E}+\mathrm{P}$, etomidate $(0.075-0.01 \mathrm{mg} / \mathrm{kg})$ followed by propofol $(0.75-1 \mathrm{mg} / \mathrm{kg})$.

depression in elderly patients when propofol is used in combination with etomidate, instead of either agent used alone, for anesthesia during gastroscopy. Co-administration of propofol and etomidate has a favorable side effect profile, allows rapid recovery to full activity and provides high levels of satisfaction.

Gastroscopy is a non-traumatic invasive procedure used for the diagnosis of gastrointestinal pathology and for treatment for gastrointestinal hemorrhage, polypus and corpus alienum (3). Elderly patients experience specific physiological changes of organs and cell functions $(15,16)$, and it is important to understand how to maintain hemodynamic stability and adequate spontaneous respiration during gastroscopy procedures in such patients. Gastroscopy is frequently performed with anesthesia for the comfort of the patient. Elderly patients requiring gastroscopy frequently have cardiovascular disease and other co-morbidities, which results in difficulties in safely administering anesthesia while maintaining stable hemodynamics. The features of gastroscopy examination require that the anesthetic regimen provides rapid induction, sufficient anesthesia, hemodynamic stability, quick recovery and minimal side effects.

Propofol is the most frequently used i.v. anesthetic to date due to its rapid recovery profile, and it has been widely used for anesthesia in outpatients $(8,9)$. However, propofol causes marked depression on hemodynamic and respiratory parameters. Hypotension is a common side effect associated with propofol due to vasodilatation and negative inotropic effects (11). An induction dose of propofol results in a $25-30 \%$ incidence of apnea and a $25-40 \%$ reduction in systolic blood pressure $(9,10)$. The high incidence of apnea, lasting longer than $30 \mathrm{sec}$, exposes patients to the potential risks of brain damage, which is the leading cause of morbidity in anesthesia-related events (17). In the present study, elderly patients induced with propofol experienced a $42 \%$ incidence of apnea, and $88 \%$ of patients experienced a significant $(>30 \%)$ reduction in systolic blood pressure. This may be related to diminished myocardial contractility, decreased cardiac output, reduced ability of the cardiovascular system to respond to stress and preoperative 
Table III. Patient satisfaction surveys of four study groups $(\mathrm{n}=50)$.

\begin{tabular}{|c|c|c|c|c|}
\hline Question and response $(\mathrm{n}=50)$ & $\mathrm{P}$ & $\mathrm{E}$ & $\mathrm{P}+\mathrm{E}$ & $\mathrm{E}+\mathrm{P}$ \\
\hline \multicolumn{5}{|l|}{$\begin{array}{l}\text { How much discomfort or } \\
\text { pain did you feel? }\end{array}$} \\
\hline None & $40(80)$ & $36(72)$ & $40(80)$ & $39(78)$ \\
\hline Mild & $8(16)$ & $12(24)$ & $9(18)$ & $10(20)$ \\
\hline Moderate & $2(4)$ & $2(4)$ & $1(2)$ & $1(2)$ \\
\hline Severe & 0 & 0 & 0 & 0 \\
\hline \multicolumn{5}{|c|}{$\begin{array}{l}\text { Rate the level of sedation received } \\
\text { during the endoscopic exam }\end{array}$} \\
\hline Adequate & $45(90)$ & $46(92)$ & $50(100)$ & $50(100)$ \\
\hline Too little & $4(8)$ & $3(6)$ & 0 & 0 \\
\hline Too much & $1(2)$ & $1(2)$ & 0 & 0 \\
\hline \multicolumn{5}{|c|}{$\begin{array}{l}\text { Rate your overall satisfaction with } \\
\text { the endoscopic sedation }\end{array}$} \\
\hline Excellent & $45(90)$ & $40(80)$ & $45(90)$ & $46(92)$ \\
\hline Good & $5(10)$ & $6(12)$ & $4(8)$ & $3(6)$ \\
\hline Fair & 0 & $4(8)$ & $1(2)$ & $1(2)$ \\
\hline Poor & 0 & 0 & 0 & 0 \\
\hline \multicolumn{5}{|c|}{$\begin{array}{l}\text { Did you require additional sleep during } \\
\text { the day after your procedure? }\end{array}$} \\
\hline Yes & $14(28)$ & $16(32)$ & $12(24)$ & $11(22)$ \\
\hline No & $36(72)$ & $34(68)$ & $38(76)$ & $39(78)$ \\
\hline \multicolumn{5}{|l|}{ How much sleep did you require? } \\
\hline None & $36(72)$ & $34(68)$ & $38(76)$ & $39(78)$ \\
\hline$<2 \mathrm{~h}$ & $9(18)$ & $11(22)$ & $9(18)$ & $8(18)$ \\
\hline $2-4 \mathrm{~h}$ & $4(8)$ & $4(8)$ & $3(8)$ & $3(8)$ \\
\hline $4-6 \mathrm{~h}$ & $1(2)$ & $1(2)$ & $0(0)$ & $0(0)$ \\
\hline \multicolumn{5}{|c|}{$\begin{array}{l}\text { When did you resume your normal daily } \\
\text { activities? }\end{array}$} \\
\hline$<2 \mathrm{~h}$ & $35(70)$ & $36(72)$ & $40(80)$ & $41(82)$ \\
\hline $2-4 \mathrm{~h}$ & $9(18)$ & $8(16)$ & $5(10)$ & $4(8)$ \\
\hline $4-6 \mathrm{~h}$ & $3(6)$ & $3(6)$ & $2(4)$ & $2(4)$ \\
\hline$>6 \mathrm{~h}$ & $3(6)$ & $2(4)$ & $3(6)$ & $3(6)$ \\
\hline
\end{tabular}

Data are $\mathrm{n}(\%)$. In the $\mathrm{P}+\mathrm{E}$ and $\mathrm{E}+\mathrm{P}$ groups, overall satisfaction was rated as excellent in 90 and $92 \%$ of patients, respectively; this is significantly higher compared with groups $\mathrm{P}$ and $\mathrm{E}(\mathrm{P}>0.05)$.

routine fasting. In contrast, etomidate is associated with hemodynamic stability and minimal respiratory depression, which are unique characteristics among rapid-onset induction agents $(11,18)$. These properties differentiate etomidate from other rapid-onset induction agents, as it has a wider margin of safety than propofol, particularly in patients with valvular heart disease, myocardial ischemia and elderly patients. The results in the current study demonstrated that there was a $14 \%$ incidence of apnea and a $12 \%$ incidence of hypotension following the use of etomidate. It is important to note that there is a significantly decrease in the incidence of apnea $(6 \%)$, and a $12 \%$ incidence of hypotension, when using propofol and etomidate together.

Cardiopulmonary complications in elderly patients have been evaluated during gastroscopy. Elderly patients who undergo gastroscopy may be at risk of developing cardiopulmonary complications resulting from preexisting cardiovascular diseases, the sympathetic response when the gastroscope is inserted through the throat, and prolonged procedure time $(5,6,19,20)$. In addition, elderly patients may be more susceptible to silent myocardial ischemia. The high incidence of ST segment depression in group P (20\%) in the present study may be related to the reduction in blood pressure resulting from an induction dose of propofol. Although 1 patient developed a very high RPP (>20), and 2 patients experienced PRQ $<1.0$, it is not sufficient to conclude that standard-dose propofol monotherapy exposes patients to a high risk of myocardial ischemia. In the current study, there were no differences in the incidence of transient atrial fibrillation, sinus bradycardia and ventricular premature complexes, 
which indicate that temporary short periods of fluctuations in blood pressure have little effect on the cardiac conduction system. Propofol is a potent hypnotic agent that can cause life-threatening side effects, including the loss of protective airway reflexes and respiratory depression $(17,21)$. In the present study, it was observed that $8 \%$ of elderly patients in group $\mathrm{P}$ required short-term positive pressure ventilation, while $2 \%$ of elderly patients in the other three groups required this intervention. This result demonstrates that etomidate has unique characteristics which allow it to be used alone or in combination with propofol for anesthesia. In addition, the results show that a combination of etomidate and propofol can result in favorable hemodynamic stability and preserve spontaneous respirations during anesthesia for gastroscopy.

Etomidate has rarely been used in outpatient operations and during examination due to side effects, such as myoclonus and PONV. Etomidate has been observed to be associated with a high (30-40\%) incidence of PONV, and the incidence of myoclonus following etomidate use is highly variable $(0-70 \%)(22,23)$, which is higher than propofol $(22)$. In the present study, the incidence of myoclonus, PONV and injection pain when etomidate combined with propofol was used and injected in different sequences, was investigated. The results demonstrate that the incidences of PONV and myoclonus in group E (14 and 30\%, respectively) are higher compared with group $\mathrm{P}$ (8 and $2 \%)$, and are reduced by combined use with propofol (10 and $12 \%$ PONV in groups $\mathrm{P}+\mathrm{E}$ and $\mathrm{E}+\mathrm{P}$, respectively; 4 and $6 \%$ myoclonus in groups $\mathrm{P}+\mathrm{E}$ and $\mathrm{E}+\mathrm{P}$, respectively). In addition, the current study observed a decreased incidence of injection pain following the combined use of propofol and etomidate. All of the results demonstrate that the combined use of propofol and etomidate results in reducedside effects, including myoclonus, injection pain and PONV, in elderly patients undergoing gastroscopy. Furthermore, the present study demonstrated that the combined use of propofol and etomidate for endoscopic anesthesia, alone or in combination, results in high levels of patient satisfaction.

In the present study, it was anticipated that a short recovery time would be accompanied by a rapid recovery to full activity. In telephone surveys conducted $24 \mathrm{~h}$ after discharge in the current study, it was reported that $72 \%$ of patients did not require additional sleep following discharge, and that $70 \%$ resumed normal activities within $2 \mathrm{~h}$ of departure from the endoscopy unit when propofol monotherapy was used, which is in agreement with the other results (8). The novel finding of the present study revealed that 76 and $78 \%$ of patients in groups $\mathrm{P}+\mathrm{E}$ and $\mathrm{E}+\mathrm{P}$, respectively, did not require additional sleep following discharge, and that 80 and $82 \%$ of patients in groups $\mathrm{P}+\mathrm{E}$ and $\mathrm{E}+\mathrm{P}$, respectively, resumed normal activities within $2 \mathrm{~h}$ of departure from the endoscopy unit. This demonstrates that the combined use of propofol and etomidate can result in a rapid return to full activity for elderly patients following gastroscopy.

The present study is subject to a number of limitations. Firstly, the current study is not a multi-center study; further research should be conducted at multiple sites. Although the study supports the hypothesis that the combined use of etomidate and propofol reduces the side effects of etomidate and propofol with minimal effects on safety and recovery, a larger trial that is sufficient to detect differences is needed to confirm these findings before a change in clinical practice is recommended. Secondly, although plasma corticosteroid concentrations were not recorded in the current study, a number of studies have demonstrated that the induction dose of etomidate can decrease plasma corticosteroid concentrations, and that this can be sustained for 6-8 h, leading to adrenocortical dysfunction (24-26). Thirdly, only the short-term hemodynamic effects on elderly patients were investigated. Although no significant difference was identified in the mortality and hospitalization among patients who received propofol or etomidate, it can not determine whether there is any effect on mortality or other aspects of clinical outcome.

In conclusion, the present study demonstrates that anesthesia for gastroscopy in elderly patients can be safely and effectively accomplished when propofol combined with etomidate is used. It is understood that these anesthetic regimens have unique characteristics, including improved hemodynamic stability, minimal respiratory depression, reduced side effects, a rapid return to full activity and high levels of satisfaction.

\section{Acknowledgements}

The authors thank patients and their families for their inclusion in the present study.

\section{References}

1. Cao H, Wang B, Zhang Z, Zhang H and Qu R: Distribution trends of gastric polyps: An endoscopy database analysis of 24121 northern Chinese patients. J Gastroenterol Hepatol 27: 1175-1180, 2012.

2. Travis AC, Pievsky D and Saltzman JR: Endoscopy in the elderly. Am J Gastroenterol 107: 1495-1501, 2012

3. Ristikankare M, Julkunen R, Heikkinen M, Mattila M, Laitinen T, Wang SX and Hartikainen J: Sedation, topical pharyngeal anesthesia and cardiorespiratory safety during gastroscopy. J Clin Gastroenterol 40: 899-905, 2006.

4. Fanti L, Agostoni M, Arcidiacono PG, Albertin A, Strini G, Carrara S, Guslandi M, Torri G and Testoni PA: Target-controlled infusion during monitored anesthesia care in patients undergoing EUS: Propofol alone versus midazolam plus propofol. A prospective double-blind randomised controlled trial. Dig Liver Dis 39: 81-86, 2007.

5. Seinelä L, Reinikainen P and Ahvenainen J: Effect of upper gastrointestinal endoscopy on cardiopulmonary changes in very old patients. Arch Gerontol Geriatr 37: 25-32, 2003

6. Cha JM, Jeun JW, Pack KM, Lee JI, Joo KR, Shin HP and Shin WC: Risk of sedation for diagnostic esophagogastroduodenoscopy in obstructive sleep apnea patients. World J Gastroenterol 19: 4745-4751, 2013.

7. Yetkin G, Oba S, Uludag M, Paksoy I, Akgün I and Eren N: Effects of sedation during upper gastrointestinal endoscopy on endocrine response and cardiorespiratory function. Braz J Med Biol Res 40: 1647-1652, 2007.

8. Cohen LB, Delegge MH, Aisenberg J, Brill JV, Inadomi JM, Kochman ML and Piorkowski JD Jr; AGA Institute: AGA institute review of endoscopic sedation. Gastroenterology 133: 675-701, 2007.

9. Kitagawa N, Katoku M, Kasahara T, Tsuruta T, Oda M and Totoki T: Does atropine reduce the risk of propofol-induced cardiovascular depression? Anesth Analg 103: 1606-1608, 2006.

10. Olofsen E, Boom M, Nieuwenhuijs D, Sarton E, Teppema L, Aarts L and Dahan A: Modeling the non-steady state respiratory effects of remifentanil in awake and propofol-sedated healthy volunteers. Anesthesiology 112: 1382-1395, 2010.

11. Morel J, Salard M, Castelain C, Bayon MC, Lambert P, Vola M, Auboyer C and Molliex S: Haemodynamic consequences of etomidate administration in elective cardiac surgery: A randomized double-blinded study. Br J Anaesth 107: 503-509, 2011.

12. Fisher L, Fisher A and Thomson A: Cardiopulmonary complications of ERCP in older patients. Gastrointest Endosc 63: 948-955, 2006. 
13. Berzin TM,Sanaka S, Barnett SR,SundarE,Sepe PS, Jakubowski M, Pleskow DK, Chuttani R and Sawhney MS: A prospective assessment of sedation-related adverse events and patient and endoscopist satisfaction in ERCP with anesthesiologist-administered sedation. Gastrointest Endosc 73: 710-717, 2011.

14. Sipe BW, Rex DK, Latinovich D, Overley C, Kinser K, Bratcher L and Kareken D: Propofol versus midazolam/meperidine for outpatient colonoscopy: Administration by nurses supervised by endoscopists. Gastrointest Endosc 55: 815-825, 2002

15. Klotz U: Pharmacokinetics and drug metabolism in the elderly. Drug Metab Rev 41: 67-76, 2009.

16. Triantafillidis JK, Merikas E, Nikolakis D and Papalois AE: Sedation in gastrointestinal endoscopy: Current issues. World J Gastroenterol 19: 463-481, 2013.

17. Wang D, Chen C, Chen J, Xu Y, Wang L, Zhu Z, Deng D, Chen J, Long A, Tang D and Liu J: The use of propofol as a sedative agent in gastrointestinal endoscopy: A meta-analysis. PLoS One 8: e53311, 2013.

18. Morel J, Salard M, Castelain C, Bayon MC, Lambert P, Vola M, Auboyer $\mathrm{C}$ and Molliex S: Haemodynamic consequences of etomidate administration in elective cardiac surgery: A randomized double-blinded study. Br J Anaesth 107: 503-509, 2011.

19. Ross R and Newton JL: Heart rate and blood pressure changes during gastroscopy in healthy older subjects. Gerontology 50 $182-186,2004$
20. Gangi S, Saidi F, Patel K, Johnstone B, Jaeger J and Shine D: Cardiovascular complications after GI endoscopy: Occurrence and risks in a large hospital system. Gastrointest Endosc 60: 679-685, 2004.

21. Oberer C, von Ungern-Sternberg BS, Frei FJ and Erb TO: Respiratory reflex responses of the larynx differ between sevoflurane and propofol in pediatric patients. Anesthesiology 103: $1142-1148,2005$

22. Wu J, Yao S, Wu Z, Wu Z, Chu S, Xia G and Deng F: A comparison of anesthetic regimens using etomidate and propofol in patients undergoing first-trimester abortions: Double-blind, randomized clinical trial of safety and efficacy. Contraception 87: 55-62, 2013.

23. Mizrak A, Koruk S, Bilgi M, Kocamer B, Erkutlu I, Ganidagli S and Oner U: Pretreatment with dexmedetomidine or thiopental decreases myoclonus after etomidate: A randomized, double-blind controlled trial. J Surg Res 159: e11-e16, 2010.

24. Schenarts CL, Burton JH and Riker RR: Adrenocortical dysfunction following etomidate induction in emergency department patients. Acad Emerg Med 8: 1-7, 2001.

25. Absalom A, Pledger D and Kong A: Adrenocortical function in critically ill patients $24 \mathrm{~h}$ after a single dose of etomidate. Anaesthesia 54: 861-867, 1999.

26. Wang N, Wang XH, Lu J and Zhang JY: The effect of repeated etomidate anesthesia on adrenocortical function during a course of electroconvulsive therapy. J ECT 27: 281-285, 2011. 